Keith Jackson*

\title{
An Essay on Sustainable Work Systems: Shaping an Agenda for Future Research
}

This essay is based on a review of the following text, now recognized internationally as being of central relevance to studies of sustainability in contexts for HRM practice and research:

- Docherty, P., Kira, M., \& Shani A. B. (eds.). (2009). Creating sustainable work systems. Abingdon: Routledge. pp. xxiii + 296, ISBN 978-0-415-77272-3.

The book reviewed here is a second (paperback) edition, and one that in turn develops on:

- Docherty, P., Forslin, J., Shani, A. B., \& Kira, M. (eds.). (2002). Creating sustainable work systems: Emerging perspectives and practices. London: Routledge.

\section{Context}

This review was drafted as the Rio+20 Earth summit was coming to a close. Its concluding document, entitled The Future $W e W$ ant, appears weak now in terms of the practical and measureable commitment displayed by international leaders to establish development objectives designed to support social, economic and technological growth that should benefit the world's populations and safeguard a natural environment such that future generations might prosper; or, as a minimum ambition, survive. The Rio earth summit took place against a background of acute and global economic uncertainty; indeed, representatives of some so-called 'developed' economies among the $20+$ continue to preside over economic meltdown: the living standards of their citizens continue on average to decline. In their role as agents influencing whether we in fact get 'the future we want', the political leaders of the $20+$ appear determined to prioritize short-term national interests over those of the planet and its future inhabitants. For example, they declare that access to drinkable water is a human right but have promised little of substance that might improve the situation of over a billion people in the world for whom easy access to water is routinely denied.

\section{Review}

Against this background we should try to understand the importance of books such as Creating Sustainable Work Systems, edited by Peter Docherty, Mari Kira and A. B. (Rami) Shani. If we are to achieve sustainable social, economic and technological growth now

\footnotetext{
* Dr. Keith Jackson, Centre for Financial and Management Studies, School of Oriental and African Studies, University of London, United Kingdom; Senior Partner, Institut für angewandte Vertrauensforschung, Stuttgart, Germany. E-mail: keith.jackson@soas.ac.uk.

management revue, 23(3), 296-309

ISSN (print) 0935-9915, ISSN (internet) 1861-9908

DOI 10.1688/1861-9908_mrev_2012_03_Jackson

(C) Rainer Hampp Verlag, www.Hampp-Verlag.de
} 
and in future, people worldwide need to be in position to work and be managed sustainably. In order to achieve this position, management practitioners and researchers the intended audience for this book - need first to understand what terms such as 'working sustainably' mean, conceptually and in practice. This book guides us towards gaining such understanding, and the fact that it appears as a second edition - a noteworthy achievement for an edited volume of this type - is testimony both to its abiding relevance and to the foresight demonstrated by publishers (in this case, Routledge) in continuing to support such projects.

The main content of the book spans seventeen chapters organized into an Introduction and five Parts, the titles of which are: Focusing value frameworks; Focusing work and work systems; Focusing change in sustainable organizations; Focusing systems; Future of sustainable work systems. Already we get a feel for the narrative being developed. Already, too, the rather idiosyncratic grammar used in these titles gives a flavor of the broad international provenance of the predominantly academic contributors to the book. The eighteen Figures and nineteen Tables distributed across the chapters add a satisfyingly vivid dimension to the narrative and the (on average) two pages of references listed at the end of each chapter offer (in most cases) a reliable guide to international research in the field. In short, the book is ably edited and well presented: it stands the test of time.

Intoning the great American songwriter Burt Bacharach, the editors use their introductory chapter (What the world needs now....) to put the ensuing discussion in context. They focus initially on highlighting the demographic shifts impacting on developed economies such as Germany: a highly skilled and increasingly ageing workforce driving a (by global comparison) highly successful export-led economy. They ask how German manufacturers might develop and implement work systems that on the one hand support the changing needs and abilities of the current and future workforces while on the other sustain productivity and thereby global competitiveness. Drawing on a United Nations resolution of 1987, Docherty and his colleagues define 'sustainability' as 'a general worldview according to which people should strive to fulfill their needs in a manner such that the ability of future generations to fulfill their needs is not endangered'. Already this invocation poses critical questions of how the other twentytwo contributors to this book might define and illustrate work systems as contexts for creating sustainability: questions that, for example, should help readers identify and predict the evolving 'needs' of people as employees and as citizens; the evolving 'needs' of organizations and the markets they target; the needs and interests of 'future generations'.

In the meantime, employers along with (for example) HRM practitioners and researchers are challenged to understand and respond to the evolving needs of current employees, such as those represented by the shifting demographic of workers within the city administration of Berlin and at the automobile manufacturer Daimler, where 'sustainability' is defined in corporate self-promotion as 'responsible corporate behavior that leads to long-term business success and is in harmony with society and the environment' (www.daimler.com, accessed 22nd June 2012). In other words, the ensuing chapters in this book should help us understand better how 'responsible' corporate behavior might be learnt and measured, how 'long-term business success' might be 
defined and achieved, and how the purported 'harmony' between society, the natural environment and (lest we forget) the corporation along with its workforce, customers and shareholders might be negotiated to the benefit of all key stakeholders involved, now and in future.

As an opening contribution towards Focusing value frameworks Keith Cox reconnects with the aforementioned Docherty et al (2002) text. In exploring 'organizational visions of sustainability' Cox develops a suitably strategic perspective by drawing on his own qualitative research, whereby business leaders are invited to recognize their opportunity to act as forces for positive social change (Cox, 2005). Taking the UK-based Body Shop brand as an example - older readers might remember its founder, Anita Roddick, being one of the first high-profile business leaders to offer the 'natural environment' a figurative seat at board level - Cox focuses on how employers might develop relationships and dialogue with employees and other key stakeholders. These relationships might be shaped by managed processes of 'purposeful reflecting' and 'nurtured' by processes of 'self-organization' along with 'cultivating' attitudes defined as 'individual mindfulness'. As to be expected when confronted by scholarly discussions of 'leadership' and 'vision', business audiences are keen to get to the valueadding coffee below the froth of conceptualization. Correspondingly, here as at the end of each chapter in this book, readers are invited to grind their own coffee in an activity prompted by 'questions for reflection'. This current chapter concludes with questions such as:

- What is your personal calling and passion? How does it relate to your organization becoming a sustainable work system?

\section{- How do you define key concepts such as sustainability and the purpose of business?}

This is a very useful device and one that elevates the book to the level of a textbook. For such questions serve not only to prompt reflection, they also guide open discussion and a critical engagement with the references listed at the end of the chapter.

The next step towards 'focusing sustainability' contextualizes the international business success of a carpeting then floor tile manufacturer (Interface) with reference to models of 'cultural incrementalism' popularized by Pasquale Gagliardi (1986). The emphasis is on a managed 'cultural revolution' in relation to organizational purpose and design: here we could invoke Finland's Nokia or Japan's Kyocera. In this second and equally term-laden chapter, Mona Amadeo proposes a 'new way of seeing' that 'removes artificial barriers between the actions of business and the consequences of those actions' (p. 48). This purported 'new way' emerges through a systematic series of re-imagining and re-creating corporate identities ('identity dynamics'), as illustrated vividly in the Figure Amadeo offers (p. 44) charting the 'transformation' of senior managers at Interface from a collective state of 'skepticism' to one of 'commitment' and on (to date) to global business success (cf. www.interface.com). It might be usefully argued that this process of transformation informs much of what we understand as industrialization throughout history. Indeed, Ray Anderson, as Chairman of Interface Inc., is given space in a Foreword to the book to remind us how early industrialization in Europe applied 'creativity' in the development of work systems in order to improve 
labor productivity rather than improve labor conditions. As increasingly 'the human foot print on the planet grows and grows at Nature's expense' (p. xxi) the challenge facing HRM researchers and practitioners today is to enhance processes of 'resource productivity'- according to Anderson, an endeavor informed by both 'enlightened self-interest' and 'necessity'.

Moving on towards Focusing work and work systems we meet Peter Brödner who develops a resource-centered perspective on knowledge-based companies, contextualized by reference to an emerging global business environment and characterized not so much by what businesses own as by what they prove able to do. Here we can recognize a distinction that is both strategically valid and invites challenge if applied critically towards gauging the performance of investment banking institutions during recent years. According to Brödner:

- Most human resources are generative in nature, i.e. they develop and grow in use due to experience (p.57).

This generalized view ('most') might appear to assume positive (e.g. perceptibly 'growth-full') experiences: how to generate and grow using experiences perceived as negative? As if to pre-empt and counter this question Brödner (p. 58) offers a model of 'strain generation' that illustrates how (in the reality of the working environment) 'project work demands' might conflict with 'contradictory work demands' at various levels, leaving spaces across which these strains might be negotiated within the real life constraints of organization-based resources. Prior to publication here Brödner had tested his model using an explorative longitudinal study among 34 employees distributed among project teams of four German employers, his stated objective being to 'capture the dynamics of knowledge-based project work and identify the impact of contradictory demands and mismatches at work' (p. 59). In the event one of the employers dropped out, thereby rendering the researcher's innovative ambition more exposed. Nonetheless, the presentation of the results generated by the study is impressive and has clear relevance towards understanding processes of sustainable business performance - the enduring challenge to management researchers and practitioners worldwide. As with several other chapters in this collection, this chapter should encourage and guide new researchers into this field of empirical enquiry. Indeed, and as highlighted here and elsewhere (cf. Brödner \& Knuth, 2002), such research prompts us to rethink the future of factories and project teams as boundaried entities that might be managed more or less sustainably.

The following chapter (five) by Julia Weichel and colleagues re-contextualizes sustainability in the context of emerging demographic shifts - in this case, 'the ageing workforce in the German car manufacturing industry' (p. 70). Both conceptual and practical insights towards 'age-based job design' are proposed, affirming in contexts for HRM, for example, that job planning and design form the foundation for assessing future employee, team and (ultimately) organizational performance (cf. Harry, 2011). The authors develop their analysis clearly and coherently by reference to various interacting and work- or task-specific 'sociotechnical sub-systems' that give the dynamic structure to organizations generally and to car manufacturers specifically. The momentum of the discussion is compelling and, as readers should expect, future- 
oriented. The highly selective and (in truth) somewhat dated list of references reflects the German context for much of the co-authors' research: students of organizational theory in English will question the lack of reference to (among others) Gareth Morgan's images of organizations as discrete social, economic, political, cultural and technological systems and (as highlighted above) sub-systems (cf. Morgan, 2007). As highlighted earlier by Morgan and Gibson Burrell, in promoting increased research attention to the challenges of sustainability we are effectively promoting paradigm shift (Burrell \& Morgan, 1979)

According to James Senna and Abraham (Rami) Shani (one of the book's coeditors), 'sustainability entails the preservation, regeneration, and development of the ecological, economic, and social resources of a system' (p. 84). Developing on the socio-technological emphasis highlighted in the preceding chapter, the authors explore the relevance of new product development (NPD) as a source designed to 'ensure' organizational survival and success. Responding to the chapter title 'utilizing technology to support sustainability' readers will recognize an opportunity to re-connect with the vast and established corpus of innovation management literature to notions of sustainability as posited above. Presenting the specific case of an unnamed software development firm (SDF), the authors state emphatically that 'sustainability means continuous strong technical leadership, continuous innovation, and ongoing development of its technical staff (p. 84) - a potent combination of strategic management priorities that elsewhere in the established innovation literature used to come under discussion of kaizen, a concept noticeably absent in the highly-structured discussion presented here. Indeed, the overtly architectural / mechanical structure of the sector-specific case study developed and conceptualized in this chapter is one of its key strengths: looking ahead, the linkages suggested in the impressive Figure (p. 89) and Table (pp. 945) offer spaces and opportunities for researchers and practitioners alike to generate general and work-specific hypotheses as a basis for testing the inputs, processes and outputs of the work systems they might choose to operate or investigate.

Having now covered one of the over three hundred pages in this book, we arrive punctually at Part Three, where the focus shifts to 'change in sustainable organizations' - a title that begs the question: what are un-sustainable organizations? Before we can answer that question, and paraphrasing from Richard Boyatzis as author of this chapter, we first need to understand how change occurs. Boyatzis has published many well-known texts about change theory, change management and team dynamics. In this chapter he focuses our attention on Intentional Change Theory (ICT) in order to emphasize how 'sustainable, desired change occurs as a discontinuous, nonlinear process through a series of emergent discoveries' (p. 103). Specific to the type of teams targeted by Peter Brödner (chapter 4), Boyatzis claims that 'the first discovery must be a shared vision', an achievement that, as we discuss subsequently, is commonly designed into the work of so-called 'communities of practice', also referred to in chapter eleven of this current collection as 'development coalitions' that might transcend the boundaries of organization- and / or task-specific teams. Boyatzis views the team as a vehicle or context for intentional change, thereby connecting with the innovation management literature where 'diversity' in team selection is promoted: i.e. team member (and leader?) selection as an HRM intervention designed to disrupt any 'comfort 
zone' attempts to pursue established routines. The discussion pursued by Boyatzis emphasizes the role or opportunity of leadership at various levels within the 'complex systems' that define innovation, sustainable (organizational) learning and, by extension, (organizational) learning about sustainability (cf. Boyatzis, 2006). Here the author offers a four level model of complex systems; namely, 'the community', 'the organization', 'the team', and 'the individual player' (p. 113). With its sophisticated and yet concise references to concepts such as Positive Emotional Attractors (PEAs) and 'resonant leadership' this chapter could act as a stand-alone. The explicit link to the overall theme of the book is consolidated in the conclusions, where the author states that 'sustainability of desired change is the key to effective change' (p. 114).

The themes of change informed and sustained by 'new' and (at times) 'painful thinking' is developed further by Lena Wilhelmson and Marianne Döös, who invoke the concept of 'sustainable heritage' in order to illustrate how the relevant actors involved might find and share (i.e. pass on) the endurance and courage required to negotiate the 'complex dynamics of sustainability' (p. 177). They develop the case study of the Swedish telecom company Ericsson and its negotiation of a series of mergers and (ultimately) break ups between 1995 and 1999. This traumatic experience became consolidated as a 'heritage' or something akin to a specifiable development in the 'organizational memory' that, having been recognized and assimilated, might support the company in future attempts to develop sustainable systems in response to the turbulence of opportunity and risk in its evolving business environment. The focus for the discussion is on 'fluctuations' or systematic changes that might be managed: e.g. fluctuations in product, in organization structure, in 'organizational principles' and, from a combined line-manager / subordinate perspective, in 'individual development'.

These observations and insights connect cohesively to chapter nine, where Michael Stebbins and Judy Valenzuela outline 'learning mechanisms in sustainable work systems design'. Conceptualized discretely as sustainable work systems (SWS) design, the authors draw on previously published research, notably that produced by Stebbins and Shani prior to the aforementioned 2002 edition of Docherty et al. Connecting explicitly with chapters four, five, six, eight and fifteen in the book, the authors develop an interpretation of sustainability that entails 'the preservation, regeneration, and development of the economic, social and ecological resources of a system' (p. 133). The authors detail a case study of the Californian health maintenance organization KPMCP and its response to changes in markets for health care provision in the United States of America. Within the company, this response became formulated in 2007 as a Clinical Management of Pharmaceuticals (CMOP) initiative - described in some detail by the authors in its application and potential as a 'learning mechanism' (p. 140). The case study is presented in some detail and would make an ideal teaching tool. As with learning (i.e. organizational, team, or individual) generally, the true test of 'sustainability' emerges over time, as evinced in the 'heritage' notion posited by Wilhelmson and Döös and / or in its re-application in other comparable organizational or strategic contexts. Correspondingly, the third 'question for reflection' at the end of this current chapter asks:

- Could the annual CMOP change process be used to orchestrate operations changes in your own organization, and if so, what kinds of learning mechanisms would be needed? 
Readers familiar with using case studies as 'learning mechanisms' might wish to add the question tag 'and why?' to the above.

Some readers might argue that the theme of the following chapter appears, in everyday business terms, somewhat overdue in the narrative developed in this book. Here Doug Cerf and Arline Savage present a 'financial management' perspective on sustainability. To those management practitioners for whom a common professional experience is of CFOs giving default negative responses to proposals to develop (for example) Sustainable HRM policies and practices, this chapter stands as a useful and highly accessible primer in how to make a structured case to secure financial resources. The authors illustrate and combine a number of more or less familiar tools and techniques: e.g. socially responsible investing (SRI), Social Return on Investment (SROI), the sustainable balanced scorecard, and measures of 'eco-efficiency' (p. 153). The authors conclude that 'financial managers in today's business environment must employ tools and techniques that support sustainability' (p. 160). In my own experience as an HRM practitioner trying to persuade financial managers to invest more sustainably in people this sentiment appears akin to wishful thinking, though such views are likely to receive solid support from the readers of this book. More realistically, I believe, working through this chapter should equip HRM practitioners and researchers with more confidence towards engaging with the discourse common (and commonly opaque?) among financial specialists.

We now reach Part Four where the focus for discussion is on (work) systems per se. Attentive readers of this review will have noticed that we have yet to tackle an explicit definition of the 'work systems' targeted for 'creation' in the book's title. Here we can remind ourselves that, in etymological terms, the word 'system' denotes something that is 'brought together' with the result that many diverse parts or 'sub-systems' are perceived to form and interact as a coherent whole. In management research we invoke systems when attempting to describe, explain, compare and (albeit speculatively) predict patterns of change. From a general management practitioner perspective, reference to existing 'systems of work' can help identify the 'as is' situation relevant to the organization and, by extension, shape decisions on what might or should be changed in order to achieve a desired 'as should be' situation (cf. Jackson, 2012). The underlying theory is that each system and - as outlined in chapter five - each organizational sub-system develops towards a dynamic state of equilibrium in response over time to pressures emanating from both within and outside each system (cf. Von Bertalanffy, 1968). In organizations and teams HR managers and project leaders generate such pressures by means of strategic interventions into existing patterns of work. The dynamic of how work systems themselves might evolve might be visualized as a basic 'I > P > O' pattern, whereby Inputs influence discernible Processes of change which, when managed, generate Outputs that in turn become Inputs to future attempts to manage change: i.e. change that, should render business organizations more sustainable, as defined variously in our discussion thus far. Consequently, the book under review can be interpreted as a potential Input into how future systems of management practice and research might be changed in order to generate Outputs that are sustainable. 
Which brings us to chapter eleven and the discussion by Svante Lifvergren and colleagues about how 'sustainability in healthcare' might be achieved by means of what the authors term a 'development coalition'. They build on the premise that 'no single organization can be sustainable if those interdependent with it are not sustainable'; and further: 'even modest achievements in sustainability cannot be realized without organizations working in concert with others in their system' (p. 167). Recalling the context given by reference to demographic shifts across both developing and developed economies, the link to healthcare as a technological and knowledge-based sub-system operating within and supportively of (for example) national social, economic and (as suggested earlier) innovation systems appears highly apposite.

Lifvergren and colleagues explain how the aforementioned 'development coalition' relevant to sustainable healthcare derives from Gustavsen et al (1997) who concluded that multiple actors in health care can develop 'joint platforms and frameworks' that support the exchange of knowledge and experiences with the potential result that they might reach a consensus of common view about what needs to be done, primarily because 'they have found it in their own best interest to support each other in a certain course of action' (Gustavsen et al, 1997:14). Consequently, a 'development coalition' is created in order to promote 'systems learning' that, according to the authors is necessary to ensure sustainable and time-relevant improvements to health care design and provision. The authors offer a detailed case study of how this might work in practice (the West Skaraborg Development Process), detailing the impact of a development (learning-based) coalition in a region of Sweden between 2001 and 2006. Readers with experience of working with and for health care providers and in the life sciences industry generally will recognize the strategic business and (not least) ethical relevance of 'questions for reflection' such as:

- How might we balance the need for routines in healthcare with practices for innovation and renewal?

By extension, readers seeking guidance in how to promote learning and sustainable improvements in business performance across sectors will recognize within the 'development coalition' concept the implication of so-called 'communities of practice' (COPs), a concept that figures prominently in the following chapter by Hilary Bradbury, who in chapter twelve outlines 'three powers of feedback for sustainable multiorganizational learning'. Drawing predictably on the work of Peter Senge, David Kolb and others, the 'three (feedback) powers' in question are defined separately and - vitally - in strategic combination as:

- Feedback among social learning actors in collaborative learning (pp. 191-2)

- Feedback from experience to continuous learning (pp. 192-3)

- Feedback between dialogue and experimentation (pp. 193-4).

In an interesting development the third feedback 'power' is linked to 'the genesis of a lifeworld, thereby making a thought-provoking bridge to the increasingly influential work of German sociologist Jürgen Habermas (cf. Habermas, 1985) before then tracking back to the author's own engagement with globally influential institutions such as 
The Sustainability Consortium in the United States of America (TSC, 2012). Aggregating from such sources, Bradbury presents a series of vignettes or mini-case studies demonstrating how the three feedback powers might support sustainability generally and specifically in relation towards developing a 'sustainable work system', defined explicitly by the author (p. 186) as:

- One that cooperates with nature's well-developed processes, allowing for feedback and selfregulation, such that activity may be sustained to meet present needs without reducing the capacity of future generations to meet their needs.

The two chapters that follow and that thereby complete Part Four of the book offer interesting and increasingly pertinent insights into how the concept of sustainable work systems extends beyond the largely HRM focus chosen for this review. For example, in a chapter on 'labeling and sustainability' Mikael Román extends the discussion towards an insightful consideration of the global market for commodities; frequently 'in crisis' - and not least from the perspective of the producers such as 'smallscale farmers' of coffee who, according to Román (p. 205), generate around seventy per cent of global production. Invoking the cause of primary commodity producers whose work is routinely exploited across the world, Román focuses his discussion on coffee as a tradable commodity and the question of whether 'voluntary regulation' in respect of 'sustainability labeling' might 'improve the environmental and socioeconomic performance in the coffee sector' (p. 214). In chapter fourteen, Sharon Moore and Julie Jie Wen offer 'an initial exploration of sustainable work systems in China', transferring what appear to be increasingly embedded western HRM concerns such as the 'work life balance' to the Chinese context. At this point the reader might ask: why not also 'explore' sustainable work systems in India, Brazil, Indonesia and South Africa? In my view such a question prompts two thoughts about this book overall. Firstly, that more research and books of this type are needed: for example, in order to further explore interpretations of the 'sustainable work system' concept across international and even global contexts for HRM. And secondly that this 2009 edition of Docherty et al's 2002 original is trying too hard to be all-inclusive in its scope: connecting with my first point (above), a reader might surmise that this book is trying to bind several books into one cover. Publishers please take note: we need more books and journals like the one under review and with sufficient cumulative impact to focus multiple stakeholder attention on the sustainability challenge. We need research that leads to positive action; and we need this sooner rather than later.

\section{Shaping a future research agenda}

Correspondingly, during the course of this review we have come to identify a number of trends that appear as themes or shared terms of reference among the contributions that together form this admirable book; notably, the impact of 'globalization' (however defined) as expressed in a series of demographic, technological and ecological shifts that, singly and in combination, have impacted on the study, design, development and comparison of sustainable work systems across the world. How did the future of these systems appear to Peter Docherty and his colleagues back in 2009? 
The concluding Part Five of the book opens with a chapter wherein Mari Kira (one of the co-editors) and Frans van Eijnatten re-connect with the definition of sustainability borrowed from the 1987 World Commission on Environment and Development as cited in the introductory chapter. To paraphrase, this 'classical description' of sustainability advocates using resources wisely and ethically in fulfillment of people's current needs while safeguarding - or (at least) 'not endangering' - the needs of future generations. The current authors' intention is to move this concern on to specific consideration of 'how employees individually and collectively can be sustained by work or, in other words, how human and social resources might be developed and integrated at work' (p. 233). The primary concept for discussion is the 'sustainable work organization', defined as 'continuously changing and developing in order to be able to function in the changing situation it faces' (p. 234). Readers might immediately ask: how is this different from the 'classical' business organization; at least, from those organizations that routinely adapt in order to survive? The subtle distinction appears to be that sustainable organizations are those that develop a so-called 'sustained functional capacity': i.e. an ability to adapt that per se becomes the focus for strategic regeneration key rather than the managed and perhaps more re-active process of adaptation itself - an emphasis that (in my view) re-connects with notions of 'organizational learning' and so on, as highlighted in previous chapters.

What is the role of individual employees in this organization-based learning process? Well, first of all they realize that the process of continuous and even predictive adaptation draws on complex sources that span 'personal and professional' boundaries and, furthermore, integrates their 'thoughts and actions' into one cumulative outcome. Employees learn how to develop and express a 'complex self (that) is able to consider even contradictory ideas and perceive the world as a many-dimensional yet integrated place'. (p. 235). Assuming they do not do it already, why should employees try? In a pre-emptive response the authors embrace the complex question of employee motivation: employees have to 'want to' find work meaningful in their use and development of skills and in interaction with others - at which point I become pedantic and suggest the term 'competences' rather than 'skills' is more appropriate here in order to capture the more complex and multi-dimensional research and application of work-based endeavor.

And what should employers or managers be doing in order to guide employees towards creating a more sustainable work system and thereby contributing towards forming a more sustainable organization? The authors specify (p. 236) three key and connected sets of interventions:

- To promote employees' mental models and comprehension of work to grow more complex

- To enable employees to take actions and learn to manage in various work situations

- To support employees' sense of meaningfulness at work.

And, how? Interestingly, the authors do not (as in some previous chapters) develop a real life case in order to illustrate how these three interventions might proceed. Rather they refer readers to the work of the influential social-psychologist Aaron Antonovsky on how individuals might learn to become more resilient to the stresses generated by 
the challenge of pursuing a healthy life: connecting to the three interventions listed above, employees can be 'supported' towards creating and sharing a pervading 'sense of coherence' in anticipation of - as opposed to 'merely' in response to - work as an inevitable source of stress (cf. Antonovsky, 1987). Managers tasked to achieve the three interventions listed above can find further practical guidance in a concise yet highly illuminative Table (p. 243) along with reference to prior research by Kira and Freling (2007).

In chapter sixteen Michael Stebbins and A. B. (Rami) Shani reconvene in an attempt to further develop the concept of SWS highlighted previously in (for example) chapter nine. Adopting an external consultant's perspective, they present a model ( $\mathrm{p}$. 251) that should render SWS design more applicable to organizational reality. They reconceptualize SWS as 'concurrent' and later as 'collaborative design', whereby 'greater attention is given to the different stakeholders, and that there is genuine participation of stakeholders at various stages of the change process' - for example, by selecting a 'design team' composed 'of both organizational members and outside experts' (p. 255). Here the role of the expert consultant becomes apparent. However, the problem remains of how value judgment such as 'greater attention' and 'genuine participation' (cited above) become operationalized - or even standardized - into practice. The authors offer a series of 'lessons from the field' (p. 258) using the example of IDEO, a design and innovation consultancy (www.ideo.com), and the input this company offered towards developing sustainability in the Palo Alto project in California. The authors use this case as a practical illustration of how collaborative SWS design might be applied in order 'to orchestrate the change process so that role overload and stress do not result' (p. 261) - an objective that re-connects with chapter fifteen above. In order that 'employees have support for local experimentation' the authors suggest that 'learning mechanisms may be the answer' (p. 262) - an expression of advice so tentative that the reader might infer a more confident connection to themes developed elsewhere in this book (chapter nine) rather that to 'lessons learned in the field'. Recognizing the conceptual and dynamic complexity of designing and conducting empirical research in fields relevant towards developing the SWS paradigm, the authors suggest that practical insights might be gained more immediately by studying the work of 'atypical' organizations such as IDEO.

\section{Sustainability: where are we now?}

We near the conclusion of our journey through the dense terrain mapped out in this book. In a concluding chapter the three editors express their views about the 'past, present and future of social sustainability'. In a series of highly illuminative Tables they identify and suggests connections between the research themes emerging at the time, and as covered in the book overall. Exploring and refining the nature of the linkages between these remains a rich source of research opportunity, as illustrated in this current Special Issue (SI) of Management Revue. Inevitably, time and research interest has moved on. However, I suggest it would be a useful learning exercise for the readers of this SI to compare what Peter Docherty and his colleagues assessed (in 2009) to be the future of research into sustainable work systems to what they have encountered in this current journal. For example, readers might be in position now to connect research 
insights and examples from sustainability management practice to the following research 'hooks' set out in 2009, selected and (except where indicated) paraphrased by me as:

- The complexity of sustainable work systems is such that researchers need to develop a holistic and interdisciplinary approach, one that embraces multi-level perspectives (p. 280).

- In a parallel endeavor, sustainability management consultants and practitioners need to allow for 'a greater level of power equality between management and co-workers, based on dialogue and collective learning' (p. 281).

- Taking the above allowance into account, empirical studies need to be designed more longitudinally than diagnostically: the research effort needs time together with on-going access to deep sources of rich data (p. 280-281).

- Research needs to be collaborative, possibly incorporating cross-disciplinary teams: participative enquiry approaches' appear conducive towards this objective (p. 282).

- Developing on the above, sustainability in both practice and research needs to be interpreted as 'a partnership' formed and sustained by the combined efforts of multiple (organizational) stakeholders (pp. 282-3). Such partnerships might be structured in practical terms around devices discussed in this book as 'learning mechanisms' (pp. 283-284).

- Developing on the above, what passes now for change and / or innovation management practice and research needs to be re-interpreted in terms relevant specifically to sustainability: e.g. by integrating attention to inputs, processes and outcomes identified as being economic, social and ecological in provenance and nature (pp. 283-284).

- Recognizing that 'sustainability is a process, not a state' (p. 287).

In their concluding comments, Docherty and his co-editors suggest that working to and with this recognition might require a similar type of 'mental revolution' among management researchers, practitioners and (as indicated above) other key stakeholders that was (in retrospect) required during the paradigm shift to 'scientific management'. Concomitantly, we might well have reached a critical fork in the path forged to such enduring effect by Frederick Taylor over one hundred years ago. Who has the courage and wit to identify and choose the sustainability path? Judging by the reported outcomes of the aforementioned Rio +20 summit, we might need to look for guidance beyond what political, economic and other established institutions appear able or willing to offer.

\section{Conclusions}

In a second Foreword to this book the eminent Harvard management expert Michael Beer asks:

- How might business organizations create a work system - the system of roles, responsibilities and relationships for getting work done - that achieves the proper balance between involvement and engagement on the one hand and life-work balance on the other? How might organizations and work be designed to ensure both high performance and employee growth and development? Organizations that are able to do this are likely to be sustained over time. 
The contributions to this book suggest a variety of conceptual and practical answers to these questions. In my view and experience there is too little detail given to measures of the 'high performance' targeted here by Michael Beer. Rather there is frequent mention of 'success'; scholarly voices dominate the discussion with far too little space given to international management practitioners and the questions they surely have about how adherence to notions of 'sustainability' might add rigorously measured operational value to the work systems they design and manage. And in this point, the 'creation' heralded in the title is largely absent: the outcomes for each chapter appear assumed; the authors appear to be 'preaching to the converted', not least to each other. And whereas the quality of the Tables, Figures along with several case studies is to be commended along with the editing of the book overall, the 'focusing' during each Part of the discussion on overtly rational models of development means (in my view) that the human element becomes swamped too often in technical jargon. In short, the tenor of this book is what we should expect from a predominantly 'western' group of researchers writing to a predominantly western audience. For apart from the brief excursion to China (chapter fourteen), global perspectives on sustainability are conspicuous by their relative absence.

And rather than constituting the obligatory 'criticism', this observed lack serves to highlight a series of future research opportunities. Around the same time as the book reviewed here was being prepared for publication more research was appearing in English by (for example) Chinese scholars on business and political leadership from a distinctly Chinese and non-western perspective (cf. Chen \& Lee, 2008). More Indian scholars were identifying and exploring processes of innovation in response to emerging markets influenced by the types of demographic, technological and ecological shift that give context to discussions of sustainability linked to business performance (cf. Budhwar \& Bhatnagar, 2008). Drawing on insights generated by their European counterparts, scholars in Brazil have been bringing a fresh enthusiasm towards reinterpreting established western paradigms (cf. Wehling et. al, 2009; de Souza Freitas et al, 2011). South Korean multi-nationals and Vietnamese managers and entrepreneurs are demonstrating that the 'can do' approach towards forming new business processes along with systems of work designed to sustain them is by no mean exclusive to 'western' contexts for management practice and research (cf. Collins, 2009; Samsung, 2012). To illustrate further, one of the distinguishing features of management in Japan has been the attempt systematically to align innovation with what nature - as represented by the annual cycle of seasonal change - appears to allow and support (cf. Jackson \& Debroux, 2009).

Together, such developments in SWS research and practice illustrate how concern for sustainability has always been international and cross-cultural in scope: it certainly attracts this relevance. For as illustrated by the book reviewed here, the sustainability challenge transcends any boundaries that might appear to divide nations, regions and academic disciplines. Consequently, it is encouraging to witness the extent to which open-access web-based sources available to HRM practitioners and researchers of SWS are becoming increasingly the norm rather than the exception (cf. SHRM, 2011). In response, I encourage readers of this review to connect with such trends 
with confidence and thereby further international research into SWS specifically and into sustainability in general.

Finally for now, I recommend that readers of this Special Issue use the book reviewed above as a rich and multi-layered source explaining how far we have come in relation to 'creating sustainable work systems', and to accept it as a guide towards recognizing how much we can still achieve.

\section{References}

Antonovsky, A. (1987). Unraveling the mystery of health - How people manage stress and stay well. San Francisco: Jossey-Bass.

Boyatzis, R. E. (2006). Intentional change theory from a complexity perspective. Journal of Management Development, 25(7), 607-623.

Brödner, P., \& Knuth, M. (eds.) (2002). Nachhaltige Arbeitsgestaltung. Trendreports zur Entwicklung und Nutzung von Humanressourcen. München, Mering: Hampp.

Budhwar, P., \& Bhatnagar, J. (eds.). (2008). The changing face of management in India. London: Routledge.

Burrell, G., \& Morgan, G. (1979). Sociological paradigms and organisational analysis. London: Heinemann.

Chen, C.-C., \& Lee, Y.-T. (2008). Leadership and management in China. Philosophies, theories and practices. Cambridge: CUP.

Collins, N. T. (2009). Economic reform and employment relations in Vietnam. London: Routledge.

Cox, C. K. (2005). Organic leadership: The co-creating of good business, global prosperity and a greener future. Unpublished thesis, Benedictine University.

de Souza Freitas, W. R., Chiapetta Jabbour, C. J., \& Almada Santos, F. C. (2011). Continuing the evolution: towards sustainable HRM and sustainable organizations. Business Strategy Series, 12(5), 226-234.

Gagliardi, P. (1986). The creation of change of organizational cultures: A conceptual framework. Organizational Studies, 7, 117-134

Gustavsen, B., Colbjørnsen, T., \& Pålshaugen, Ø. (1997). Development coalitions in working life. Amsterdam: John Benjamins.

Habermas, J. (1985). The theory of communicative action. Boston MA: Beacon Press.

Harry, W. (2011). Job planning. In C. Rowley \& K. Jackson (eds.). (2011). Human resource management: The key concepts (pp. 113-117). London: Routledge.

Jackson, K. (2012). Management systems and styles in East Asia. In M. Warner (ed.). (2012). Managing across diverse cultures in Asia: Issues and challenges in a changing world. London: Routledge.

Jackson, K., \& Debroux. P. (2009). Innovation in Japan: Emerging patterns, enduring myths. London: Routledge.

Kira, M., \& Freling, E. (2007). Bureaucratic boundaries for collective learning in industrial work. Journal of Workplace Learning, 19(5), 296-310.

Morgan, G. (2007). Images of organization. New York: Sage.

Rowley, C. \& Jackson, K. (eds.). (2011). Human resource management: The key concepts. London: Routledge.

Samsung (2012). Sustainability report 2012. www.samsung.com, accessed 24th July 2012.

SHRM (2011). Advancing sustainability: HR's role survey report - A research report by the Society for Human Resource Management, BSR and Aurosoorya. www.shrm.org, accessed $20^{\text {th }}$ July 2012.

TSC (2012). The sustainability consortium. www.sustainabilityconsortium.org, accessed 30 ${ }^{\text {th }}$ June, 2012.

von Bertalanffy, L. (1968). General system theory: Foundations, development, applications. New York: Brazilier.

Warner. M. (ed.). (2012). Managing across diverse cultures in Asia: Issues and challenges in a changing world. London: Routledge.

Wehling, C., Hernandez, A. G., Osland, J., Osland, A., Deller, J., Tanure, B., Neto, A. C., \& Sairaj, A. (2009). An exploratory study of the role of HRM and the transfer of German MNC sustainability values to Brazil. European Journal of International Management, 3(2), 176-198. 